\title{
Relations between circulating and myocardial fibrosis-linked microRNAs with left ventricular reverse remodeling in dilated cardiomyopathy
}

\author{
Ewa Dziewięcka ${ }^{1, B-D}$, Justyna Totoń-Żurańska ${ }^{2, B, C}$, Paweł Wołkow ${ }^{2, B, C}$, Maria Kołton-Wróż',B,, \\ Ewelina Pitera ${ }^{2, B, C}$, Sylwia Wiśniowska-Śmiałek',B, , Lusine Khachatryan ${ }^{3, B}$, Aleksandra Karabinowska, ${ }^{3, B}$, \\ Maria Szymonowicz ${ }^{3, B}$, Piotr Podolec ${ }^{1, E}$, Paweł Rubisi, $1, A, C, E, F$ \\ ${ }^{1}$ Department of Cardiac and Vascular Diseases, John Paul II Hospital, Kraków, Poland \\ ${ }^{2}$ Center for Medical Genomics OMICRON, Jagiellonian University Medical College, Kraków, Poland \\ ${ }^{3}$ Jagiellonian University Medical College, Students' Scientific Group at the Department of Cardiac and Vascular Diseases, John Paul II Hospital, Kraków, Poland \\ A - research concept and design; $\mathrm{B}$ - collection and/or assembly of data; $\mathrm{C}$ - data analysis and interpretation; \\ $D$ - writing the article; $E$ - critical revision of the article; $F$ - final approval of the article
}

Address for correspondence

Ewa Dziewięcka

E-mail: ewa@dziewiecka.pl

\section{Funding sources}

This work was funded by the National Science Centre of Poland (grant No. 2013/09/D/NZ5/00252)

and the Department of Scientific Research and Structural Funds of Jagiellonian University Medical College (grant No. K/ZDS/004596).

Conflict of interest

None declared

Received on September 26, 2018 Reviewed on September 11, 2019 Accepted on December 5, 2019

Published online on March 24, 2020

Cite as

Dziewięcka E, Totoń-Żurańska J, Wołkow P, et al. Relations between circulating and myocardial fibrosis-linked microRNAs with left ventricular reverse remodeling in dilated cardiomyopathy. Adv Clin Exp Med. 2020;29(3):285-293. doi:10.17219/acem/115088

DOI

10.17219/acem/115088

Copyright

Copyright by Author(s)

This is an article distributed under the terms of the

Creative Commons Attribution 3.0 Unported (CC BY 3.0)

(https://creativecommons.org/licenses/by/3.0/)

\begin{abstract}
Background. Left ventricular reverse remodeling (LVRR) determines clinical status and outcomes in dilated cardiomyopathy (DCM). The extent of myocardial fibrosis is connected to the systolic function of the heart. The recent discovery of the contribution of microRNAs (miRs) to the regulation of cardiac remodeling, LVRR and fibrosis warrants exploration.

Objectives. The aim of the study was to examine the predictive value of circulating and myocardial miR expression for LVRR in DCM.

Material and methods. Seventy consecutive DCM patients (age $48 \pm 12.1$ years, $90 \%$ male, ejection fraction (EF) $24.4 \% \pm 7.4 \%$ ) were included in the study. At baseline, all patients underwent clinical assessment, echocardiography, venous blood sampling, and right ventricular endomyocardial biopsy. Circulating and myocardial miRs (miR-21, -26, -29, -30,-133a, and -423) were measured with quantitative real-time polymerase chain reaction ( $q R T-P(R)$. LVRR was defined as an increase in $E F \geq 10 \%$, accompanied by a decrease in left ventricle end-diastolic diameter (LVEDd) $\geq 10 \%$ or LVEDd $\leq 33 \mathrm{~mm} / \mathrm{m}^{2}$ between baseline and 3-month follow-up.
\end{abstract}

Results. At the 3-month follow-up, 4 patients had died and 3 patients had incomplete data. The remaining patients were divided according to the presence of LVRR into LVRR-present $(n=32,51 \%)$ and LVRR-absent ( $n=31,49 \%$ ) groups. Out of all the circulating and tissue miRs under study, only myocardial expression of miR-133a significantly differed between the LVRR-present and LVRR-absent group (1.22 (0.47-1.90) vs 0.61 $(0.25-0.99) \Delta C q$, respectively, $p<0.01)$. miR-133a was found to be a significant LVRR predictor in unadjusted (odds ratio $(O R)=2.81(1.23-6.40), p<0.05)$ and adjusted for duration of disease, left ventricle end-diastolic (LVED) volume (LVEDvol), hs-troponin-T, and NT-proBNP $(0 R=5.20(1.13-24.050, p<0.05)$ models.

Conclusions. From all of the circulating and tissue miRs, only myocardial miR-133a showed increased expression in LVRR-present patients and was found an independent LVRR predictor. This indicates a link between miR-133 and cardiac remodeling in DCM.

Key words: microRNA, dilated cardiomyopathy, left ventricle reverse remodeling 


\section{Introduction}

Heart failure (HF) is a worldwide problem with a prevalence of $1-2 \%$ in the general population. ${ }^{1}$ In a younger population, between 20 and 40 years of age, the most common HF etiology is dilated cardiomyopathy (DCM). ${ }^{2}$ It is a progressive myocardial disease, characterized by ventricular wall thinning and dilation accompanied by gradual functional impairment. ${ }^{3}$ During the progression of the disease, the left ventricle (LV) undergoes profound adverse morphological and functional changes, termed remodeling. This process has a crucial role in the transition from the compensated and oligo-symptomatic DCM phenotype to overt and symptomatic HF. Cardiac fibrosis contributes to adverse remodeling. ${ }^{4}$

Following optimal medical therapy, in approx. $30-50 \%$ of DCM patients, the heart - and the LV in particular - can undergo LV reverse remodeling (LVRR). This is a broad term that describes beneficial changes in LV morphology (decrease of LV size) and function (improvement of LV systolic function). ${ }^{5,6}$ The current recommendations of the European Society of Cardiology (ESC) on HF management take the possibility of the occurrence of LVRR into account and emphasize the need for regular monitoring of cardiac morphology and function. ${ }^{1}$ Since LVRR is one of the strongest prognostic predictors in HF and DCM, many investigations have been carried out to determine LVRR predictors. ${ }^{5}$ Despite huge efforts being made towards LVRR prediction as well as the treatment of HF through LVRR induction, HF is still one of the most common causes of mortality worldwide.

The recent discovery of the contribution of microRNAs (miRs) to the regulation of cardiac remodeling and fibrosis suggests their potential diagnostic and therapeutic role. In mice, up- and downregulation of specific miRs were found to be related to various aspects of cardiac pathology. 7,8 From previous studies, miR-21, miR-26, miR-29, miR-30, miR-33a, and miR-133a are known to be related to myocardial fibrosis, cardiac remodeling and cardiac hypertrophy., ${ }^{9,10}$ These miRs are believed to be valuable biomarkers of cardiac diseases; however, their relations with LVRR in DCM is currently unknown.

\section{Methods}

\section{Study population}

Seventy consecutive DCM patients with a clinical and echocardiographic diagnosis of DCM (63 men and 7 women, with an average age of $48 \pm 12.1$ years), admitted to the cardiology clinic between July 2014 and October 2015, were included in the study. All patients were willing to participate in the study. During the study, 4 patients died and 3 patients had incomplete data before the $3^{\text {rd }}$ month of follow-up. For the purposes of this study, we analyzed 63 of the 70 patients
(84\%) with available laboratory and echocardiographic data at baseline evaluation and after 3 months.

Dilated cardiomyopathy was diagnosed by the presence of LV dilation (>117\% of predicted LV end diastolic diameter (LVEDd)) and impaired LV systolic function (ejection fraction (EF) <35\%) shown on detailed echocardiogram, after the exclusion of significant coronary artery disease, arterial hypertension, congenital heart disease, and primary heart valve disease - in line with the current ESC 2017 recommendations. ${ }^{3}$ Moreover, patients were excluded from the study based on the presence of chronic liver insufficiency, neoplasms, peripheral atherosclerosis, as well as bone and joint diseases affecting collagen metabolism and circulating levels of procollagens. All patients had optimal HF therapy with regards to drug type and dosage, and stable HF symptoms (according to the New York Heart Association (NYHA) scale) for at least 2 weeks before inclusion in the study.

This study was approved by the Jagiellonian University Ethics Committee (protocol No. KBET/164/B/2014, date of approval: June 30, 2014). Written informed consent was obtained from all participants prior to inclusion in the study. All procedures performed were in accordance with the ethical standards of the institutional research committee and the 1964 Helsinki declaration and its later amendments, or comparable ethical standards.

\section{Study design}

All patients underwent detailed clinical assessment, laboratory tests, echocardiography, electrocardiography, cardiopulmonary exercise, and right ventricular endomyocardial biopsy at the baseline of the study. All subjects were also evaluated at the $3^{\text {rd }}$ month of follow-up and underwent clinical and echocardiography examination.

\section{Right ventricular biopsy}

Endomyocardial biopsy procedures were performed by experienced operators via a femoral or jugular vein approach. Long, flexible biopsy forceps (7 French size) with small jaws (Cordis ${ }^{\circledR}$; Johnson \& Johnson Co, Miami Lakes, USA) were used. Up to 5 myocardial samples were obtained from the RV septum and then stored in formalin for light microscopic examinations of fibrosis (2-3 samples) or frozen in OCT-embedding medium and then stored at $-80^{\circ} \mathrm{C}$ for further studies (2 samples; Fig. 1).

\section{Laboratory measurements}

At baseline, venous blood samples were drawn in a fasted state in the morning after $30 \mathrm{~min}$ of supine rest. All venous blood samples, after centrifuge, were stored at $-20^{\circ} \mathrm{C}$ until assay. Before examination, small tissue samples from the right ventricular biopsy from the baseline were homogenized. Levels of circulating and tissue miRs were established with quantitative polymerase chain reaction 


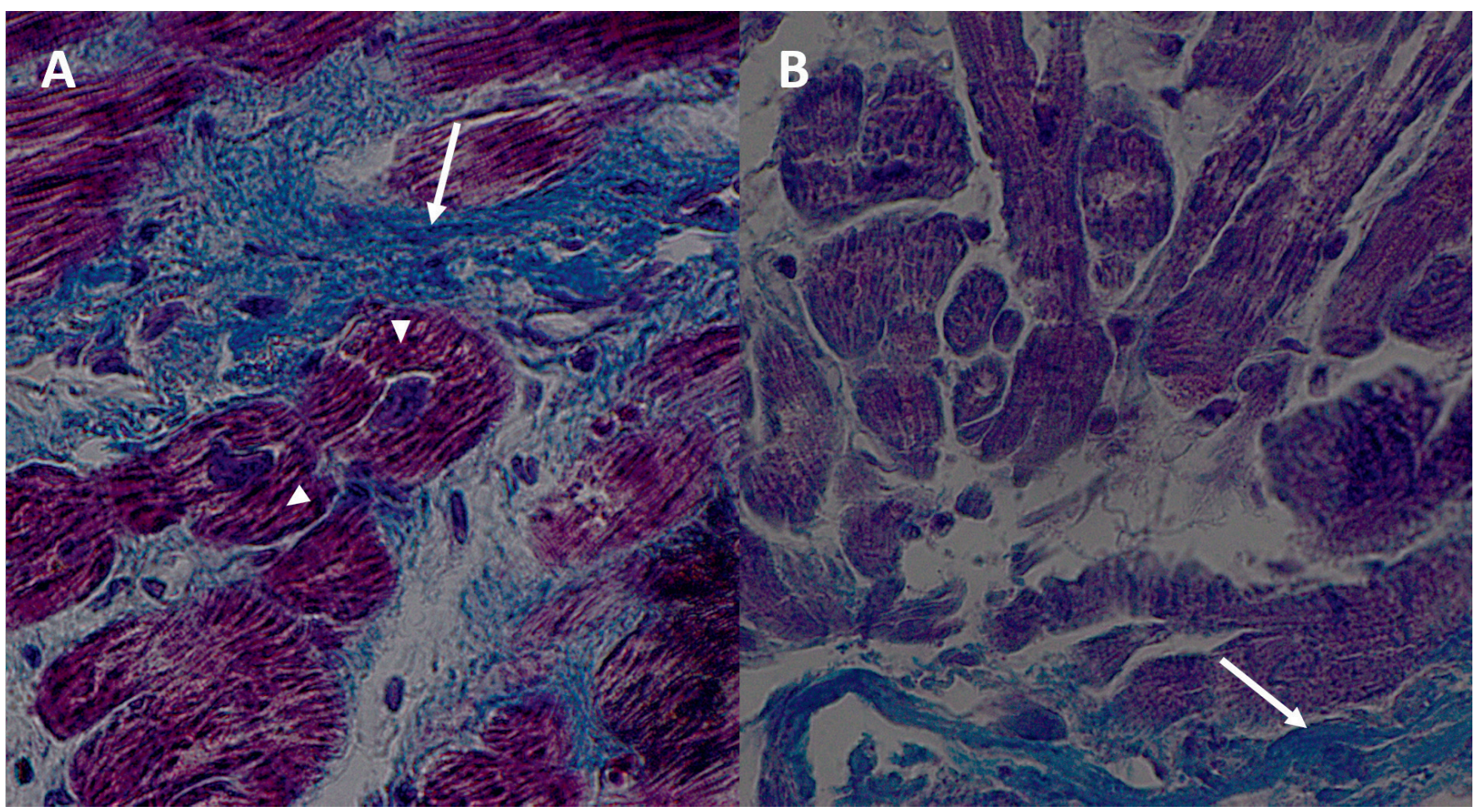

Fig. 1. Right ventricular bioptates. Biopsy specimens stained with collagen specific Masson's trichrome. Panel A - massive diffuse (interstitial) fibrosis (arrowheads). Compression of the adjacent myocytes (arrows). Panel B - widespread endocardial fibrosis (arrowheads)

(qPCR). ${ }^{11}$ With a MirVana kit (Life Technologies, Carlsbad, USA) and according to the manufacturer's protocol, RNA was extracted from $100 \mu \mathrm{L}$ of sample. Then, with a TaqMan Advanced MicroRNA cDNA Synthesis Kit (Life Technologies), reverse transcription was performed on $2 \mu \mathrm{L}$ of extracted RNA. After $\times 10$ dilution of the cDNA samples, the qPCR reaction was conducted with TaqMan Advanced MasterMix and TaqMan Advanced Assays on 384-well plates. The qPCR targeted hsa-miR-21-5p, hsa-miR-26a-5p, hsa-miR-29b-3p, hsa-miR-30a-3p, hsa-miR-30c-5p, and hsa-miR-133a-3p. Fifteen-microliter reactions were prepared with the Bravo pipetting station (Agilent Technologies, Santa Clara, USA) and the real-time qPCR reaction (RT-qPCR) was run and read on the CFX384 Real Time PCR Detection System (Bio-Rad Laboratories, Hercules, USA). We tested miR-423, selected on the basis of our previous experience with qPCR in plasma samples. Mean quantitation cycle $(\mathrm{Cq})$ values were normalized to the geometric mean of hsa-miR-423, which was selected as a relatively stable control in pilot experiments. Data was expressed for each sample as $\Delta \mathrm{Cq}$, which is the difference between the Cqualue, the miRNA of interest and the geometric mean of miR-423 for a particular sample.

\section{Echocardiography}

All echocardiographic examinations were performed in accordance with the recent European and American recommendations. ${ }^{12}$ Volumetric and EF measurements were performed in apical 4- and 2-chamber views, utilizing the method of disk summation - modified Simpson's rule. All echocardiographic parameters were calculated as the mean of 3 measurements for patients with sinus rhythm, and of 5 measurements for patients with atrial fibrillation. Chamber diameters, areas and volumes were normalized for body surface area (BSA). All examinations were made on commercially available equipment (Vivid 7 GE Medical System, Horten, Norway) with a phased-array of $1.5-4 \mathrm{MHz}$ transducer by experienced echocardiographers.

\section{Definition of LVRR}

Left ventricle reverse remodeling was defined as an absolute increase in EF of minimum 10\%, with a simultaneous decrease in LVEDd of at least $10 \%$ or an indexed LVEDd under $33 \mathrm{~mm} / \mathrm{m}^{2}{ }^{5}$ Left ventricular reverse remodeling was calculated between the baseline and $3^{\text {rd }}$ month of follow-up measurements (Fig. 2).

\section{Statistical analysis}

Tissue and circulating levels of miRs are presented as median and quartiles, and other parameters as mean \pm standard deviation (SD). All variables were tested for normal distribution of the data with the Shapiro-Wilk test. Comparisons of clinical and echocardiographic parameters between the LVRR-present and LVRR-absent groups were conducted with t-tests when normality was confirmed, or with a Mann-Whitney test for parameters without a normal distribution. The impact of circulating and 


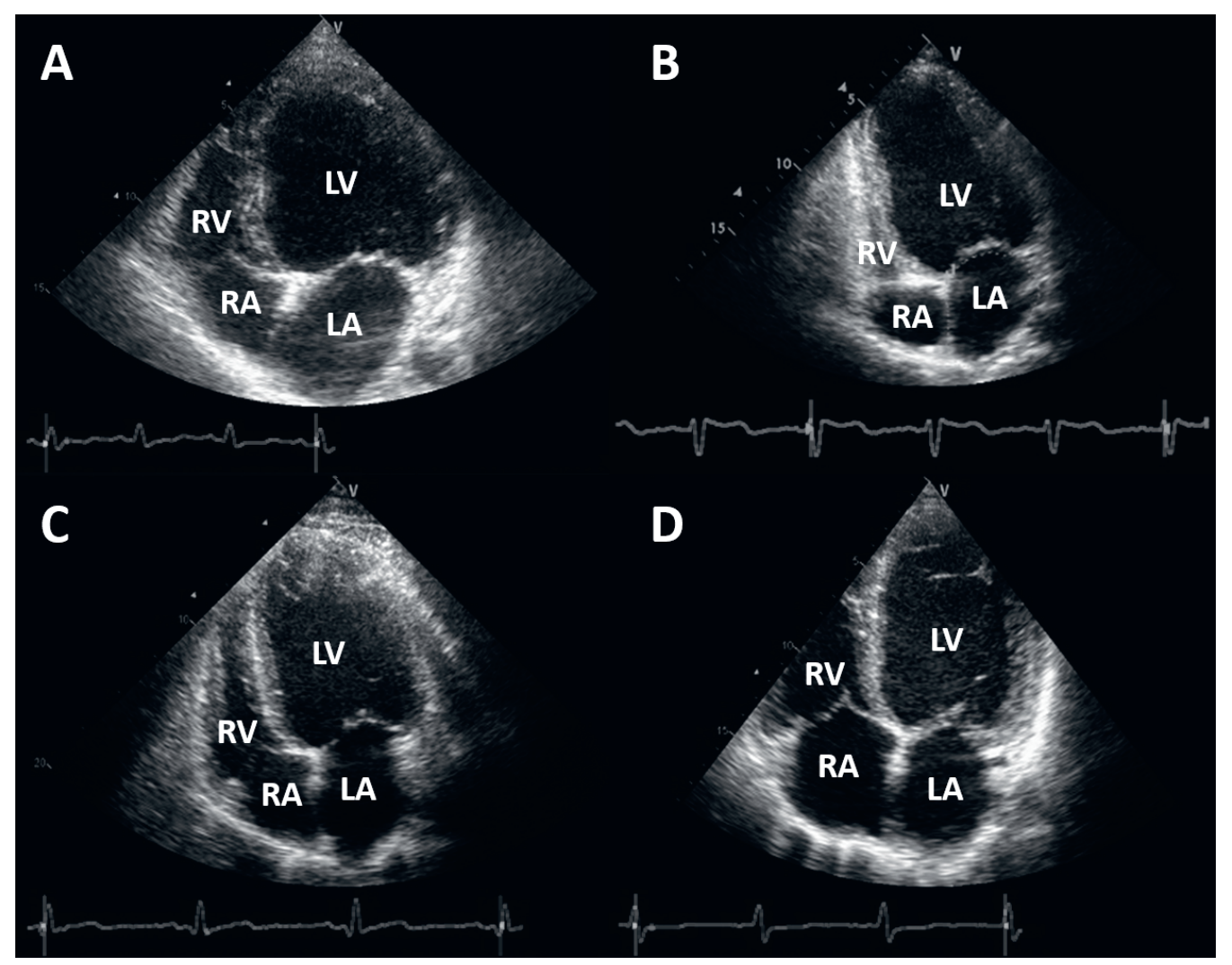

Fig. 2. Apical four-chamber echocardiographic projections. Panel A and B - patient with LVRR ( $A$ - at baseline echo, showing grossly enlarged, thin-walled LV with severely impaired LV systolic function, EF - 22\%; B - substantial decrease of LV cavity size alongside improvement of LV systolic function, $E F-42 \%)$. Panel $C$ and $\mathrm{D}$ - patient without LVRR (C - baseline echo; D - lack of improvement of LV size and systolic function)

LV - left ventricle; LA - left atrium; $\mathrm{RV}$ - right ventricle; RA - right atrium; LVRR - left ventricular reverse remodeling.

myocardial tissue miRs on the probability of LVRR was analyzed with uni- and multivariate logistic regression methods. Areas under the receiver operating characteristics (ROC) curves (areas under the curve (AUC)) were used to establish the most optimal cut-off values of the analyzed parameters and their diagnostic accuracy. For regression analysis, $\log 10$ of the NT-proBNP level was used. All results were considered statistically significant when $\mathrm{p}$-value was $<0.05$. The STATISTICA package v. 13.0 (StatSoft, Inc., Tulsa, USA) was used for the statistical analysis.

\section{Results}

\section{Baseline characteristics}

Sixty-three patients with complete data were divided according to the presence of LVRR: an LVRR-present group ( $\mathrm{n}=32,51 \%)$ and an LVRR-absent group ( $\mathrm{n}=31,49 \%)$. Compared with the LVRR-absent individuals, LVRR-present patients were characterized by a shorter duration of $\mathrm{HF}$ symptoms ( $\mathrm{p}<0.01$ ), a smaller LV dimension (LVEDd, $\mathrm{p}<0.001$ ) and volume (LVEDvol, $\mathrm{p}<0.001$ ), as well as lower serum levels of troponin $(\mathrm{p}<0.05)$ and NT-proBNP $(\mathrm{p}<0.01)$ (Table 1).

\section{Comparison of miRNA plasma and tissue levels}

Expression of all circulating miRs were similar in both groups. However, myocardial expression of miR-133 was significantly higher in patients with LVRR $(\mathrm{p}<0.01)$ (Table 2).

\section{The predictive value of clinical, echocardiographic and laboratory parameters for LVRR}

All parameters, including symptom duration time, LVEDvol, troponin, NT-proBNP and myocardial miR-133a, that differentiated LVRR-present and LVRR-absent were found to be LVRR predictors in ROC analyses and univariate regression. The respective results are presented in the Table 3 and Fig. 3A-E. Finally, only LVEDvol and miR-133 were found to be significant predictors in multivariate analysis, adjusted for symptom duration time, and troponin (hs-TnT) and NT-proBNP levels (Table 4). The combined model was found to be superior compared to models with only a single variable (AUC $=0.93,95 \% \mathrm{CI}=0.85-1.00$; specificity $85 \%$ and sensitivity $87.5 \%$ ) (Fig. 3F). 
Table 1. Baseline characteristics of the study population, divided into groups with and without LVRR

\begin{tabular}{|c|c|c|c|}
\hline Parameter & $\begin{array}{l}\text { LVRR-present group } \\
\qquad(\mathrm{n}=32,51 \%)\end{array}$ & $\begin{array}{l}\text { LVRR-absent group } \\
\qquad(\mathrm{n}=31,49 \%)\end{array}$ & p-value \\
\hline Age [years] & $48.9 \pm 9.9$ & $46.9 \pm 9.9$ & 0.53 \\
\hline Sex [male] & $29(90.6 \%)$ & $28(90.3 \%)$ & 0.97 \\
\hline $\mathrm{BMI}\left[\mathrm{kg} / \mathrm{m}^{2}\right]$ & $28.3 \pm 4.8$ & $25.9 \pm 5.5$ & 0.07 \\
\hline NYHA class & $2.56 \pm 0.84$ & $2.48 \pm 0.57$ & 0.74 \\
\hline HF symptoms' duration [ms] & $14.7 \pm 29.9$ & $35.8 \pm 40.8$ & 0.005 \\
\hline QRS [ms] & $102.8 \pm 30.0$ & $114.5 \pm 36.0$ & 0.24 \\
\hline LVEDd/BSA [mm/m²] & $31.7 \pm 4.1$ & $39.5 \pm 6.6$ & 0.02 \\
\hline LVEDvol/BSA [mL/m²] & $101.5 \pm 36.3$ & $151.6 \pm 72.0$ & 0.02 \\
\hline EF [\%] & $25.8 \pm 7.6$ & $22.3 \pm 6.7$ & 0.07 \\
\hline LAA [mm] & $31.1 \pm 8.3$ & $30.4 \pm 9.2$ & 0.77 \\
\hline PA mean $[\mathrm{mm} \mathrm{Hg}]$ & $21.0 \pm 9.3$ & $24.2 \pm 12.2$ & 0.33 \\
\hline $\mathrm{VO}_{2}$ peak $[\mathrm{mL} / \mathrm{kg} / \mathrm{min}]$ & $15.7 \pm 4.5$ & $16.4 \pm 7.0$ & 0.78 \\
\hline $\mathrm{Hb}[\mathrm{g} / \mathrm{dL}](14.0-18.0)$ & $14.8 \pm 1.6$ & $14.3 \pm 1.4$ & 0.21 \\
\hline CK-MB [U/L] (UNL < 24) & $12.9 \pm 4.9$ & $13.5 \pm 5.5$ & 0.52 \\
\hline hs-TnT [ng/mL] (UNL < 0.014) & $0.016 \pm 0.01$ & $0.028 \pm 0.02$ & 0.02 \\
\hline hs-CRP [mg/dL] (UNL < 3.0) & $11.9 \pm 29.2$ & $7.7 \pm 18.9$ & 0.07 \\
\hline NT-proBNP $[\mathrm{pg} / \mathrm{mL}](\mathrm{UNL}<125)$ & $2,606 \pm 5,041$ & $4,242 \pm 6,268$ & 0.009 \\
\hline TGF- $\beta[\mathrm{pg} / \mathrm{mL}](4,639-1,4757)$ & $2,867 \pm 1,472$ & $2,358 \pm 975$ & 0.22 \\
\hline CTGF $[\mathrm{ng} / \mathrm{mL}](2.3-42.5)$ & $5.63 \pm 4.56$ & $4.68 \pm 2.96$ & 0.55 \\
\hline Galectin-3 [ng/mL] (8.6-10.9) & $13.8 \pm 4.49$ & $14.4 \pm 4.20$ & 0.55 \\
\hline CRT & $5(15.6 \%)$ & $15(48 \%)$ & 0.005 \\
\hline$\beta$-blocker & $31(96.9 \%)$ & $31(100 \%)$ & 0.32 \\
\hline ACE-I & $31(96.9 \%)$ & $29(93.5 \%)$ & 0.54 \\
\hline MRA & $31(96.9 \%)$ & $28(93.1 \%)$ & 0.29 \\
\hline Furosemide & 19 (59.4\%) & $19(61.3 \%)$ & 0.88 \\
\hline
\end{tabular}

Data is presented as mean \pm SD or $n$ (\%). BMI - body mass index; NYHA - New York Heart Association class; LVEDd/BSA - indexed LV end-diastolic diameter; LVEDvol/BSA - indexed LV end-diastolic volume; EF - ejection fraction; LAA - left atrium area; PA mean - mean pulmonary artery pressure; VO 2 peak - peak oxygen uptake; $\mathrm{Hb}$ - hemoglobin, CK-MB - myocardial fraction of creatine kinase; hs-TnT - high sensitivity troponin T; hs-CRP - high sensitivity C-reactive protein; NT-proBNP - amino-terminal pro B-type natriuretic peptide; TGF- $\beta$ - transforming growth factor $\beta$; CTGF - connective tissue growth factor; CRT - cardiac resynchronization therapy; ACE-I - angiotensin converting enzyme inhibitor; MRA - mineralocorticoid receptor antagonist; UNL - upper normal limit.

Table 2. Comparison of plasma and cardiac tissue levels of selected microRNAs in patients with and without LVRR

\begin{tabular}{|c|c|c|c|}
\hline microRNA & LVRR-present group $(n=32)$ & LVRR-absent group $(n=31)$ & $p$-value \\
\hline $\operatorname{miR}-21[\triangle \mathrm{Cq}]$ & $0.19(-0.12-0.50)$ & $0.02(-0.41-0.77)$ & 0.77 \\
\hline $\operatorname{miR}-26[\Delta \mathrm{Cq}]$ & $-0.25(-0.62-0.14)$ & $0.33(-0.64-0.94)$ & 0.12 \\
\hline $\operatorname{miR}-29[\Delta C q]$ & $2.87(2.49-3.18)$ & $2.72(2.40-3.08)$ & 0.81 \\
\hline miR-30a3 $[\Delta \mathrm{Cq}]$ & $7.98(6.73-8.78)$ & $7.77(6.82-9.43)$ & 0.86 \\
\hline $\operatorname{miR}-30 c 5[\triangle C q]$ & $4.31(3.86-4.81)$ & $4.03(3.73-4.82)$ & 0.65 \\
\hline $\operatorname{miR}-133 a[\Delta C q]$ & $6.99(6.31-8.94)$ & $7.60(5.73-9.07)$ & 0.59 \\
\hline $\operatorname{miR}-423[\triangle \mathrm{Cq}]$ & $-0.25(-0.62-0.14)$ & $0.33(-0.64-0.94)$ & 0.12 \\
\hline Tissue miR-21 [ $\Delta \mathrm{Cq}]$ & $1.33(0.73-1.92)$ & $1.01(0.40-1.47)$ & 0.09 \\
\hline Tissue miR-26 [ $\triangle \mathrm{Cq}]$ & $-1.33(-1.77--0.92)$ & $-1.41(-1.72--0.97)$ & 0.54 \\
\hline Tissue miR-29a $[\Delta C q]$ & $1.49(0.87-1.91)$ & $1.16(0.64-1.51)$ & 0.17 \\
\hline Tissue miR-29b $[\Delta C q]$ & $1.38(0.72-2.07)$ & $1.07(0.65-1.63)$ & 0.21 \\
\hline Tissue miR-30c $[\Delta C q]$ & $-0.51(-1.01-0.19)$ & $-0.73(-1.03--0.18)$ & 0.26 \\
\hline Tissue miR-133a [ $\Delta \mathrm{Cq}]$ & $1.22(0.47-1.90)$ & $0.61(0.25-0.99)$ & 0.006 \\
\hline
\end{tabular}

Data is presented as median and $95 \%$ confidence interval $(95 \% \mathrm{Cl})$. 
Table 3. Odds ratios (OR) and ROC analysis for LVRR prediction from univariate logistic regression analysis

\begin{tabular}{|c|c|c|c|c|c|}
\hline \multirow{2}{*}{ Parameter } & \multicolumn{2}{|c|}{ Univariate logistic regression } & \multicolumn{2}{|c|}{ ROC analysis } & \multirow{2}{*}{$\begin{array}{c}\text { Cut-off value } \\
\text { (specificity, sensitivity) }\end{array}$} \\
\hline & OR $(95 \% \mathrm{Cl})$ & $p$-value & $\operatorname{AUC}(95 \% \mathrm{Cl})$ & $p$-value & \\
\hline Duration of disease [months] & $0.98(0.97-0.99)$ & 0.049 & $0.70(0.57-0.83)$ & 0.002 & $3(68 \%, 63 \%)$ \\
\hline LVEDvol $\left[\mathrm{mL} / \mathrm{m}^{2}\right]$ & $0.993(0.987-0.999)$ & 0.02 & $0.68(0.55-0.82)$ & 0.009 & $187(84 \%, 50 \%)$ \\
\hline hs-TnT [ng/mL] & $<0.0001(0-0.022)$ & 0.03 & $0.69(0.55-0.83)$ & 0.007 & $0.011(79 \%, 50 \%)$ \\
\hline NT-proBNP [pg/mL] & $0.29(0.11-0.78)$ & 0.02 & $0.70(0.56-0.83)$ & 0.005 & $826(90 \%, 48 \%)$ \\
\hline $\operatorname{miR}-133 a[\Delta C q]$ & $2.81(1.23-6.40)$ & 0.015 & $0.71(0.56-0.85)$ & 0.003 & $1.016(77 \%, 63 \%)$ \\
\hline
\end{tabular}

Duration of disease, LVED volume (LVEDvol), troponin (hs-TnT), NT-proBNP and myocardial miR-133a levels as LVRR predictors in univariate logistic regression

A HF symptoms' duration time

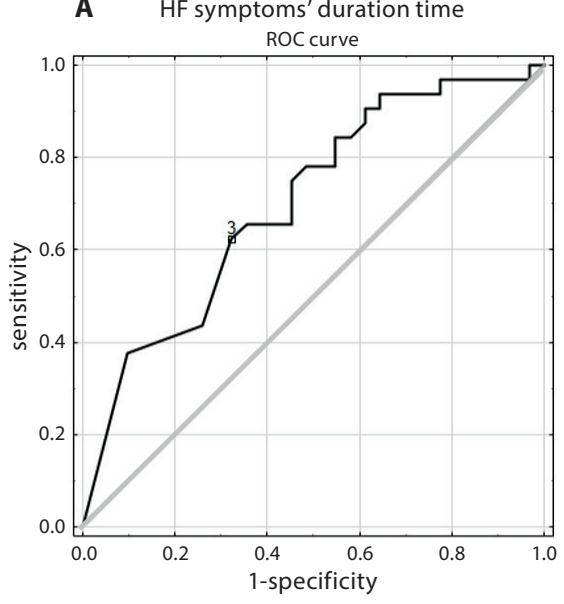

D

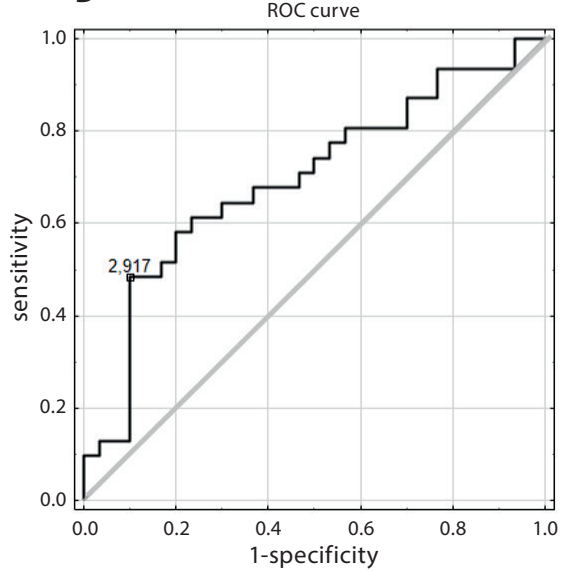

B left ventricle end-diastolic volume

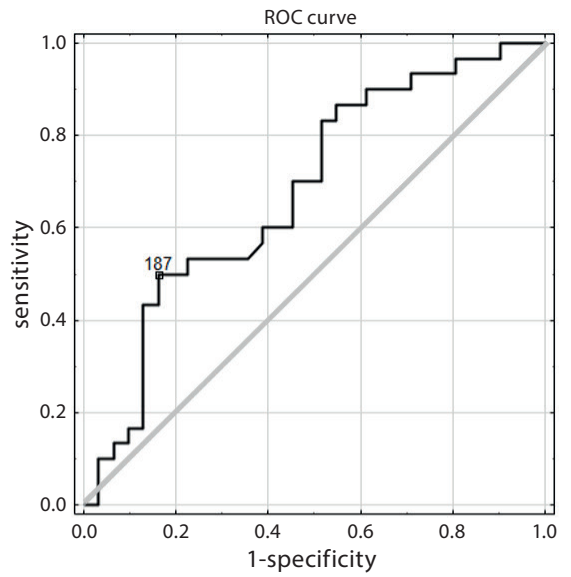

E microRNA-133a level

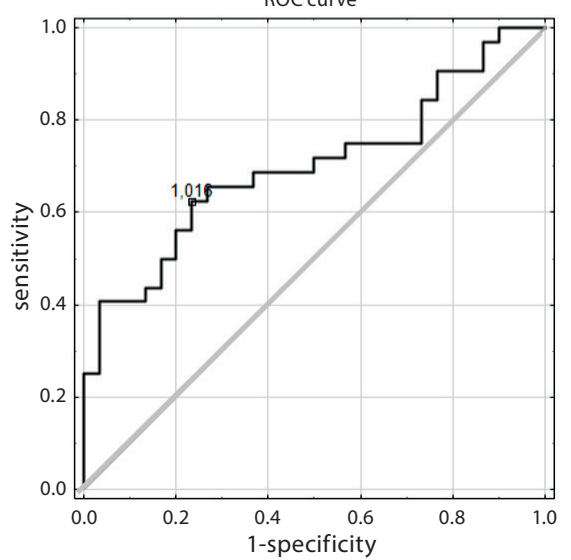

C hs-troponin T level

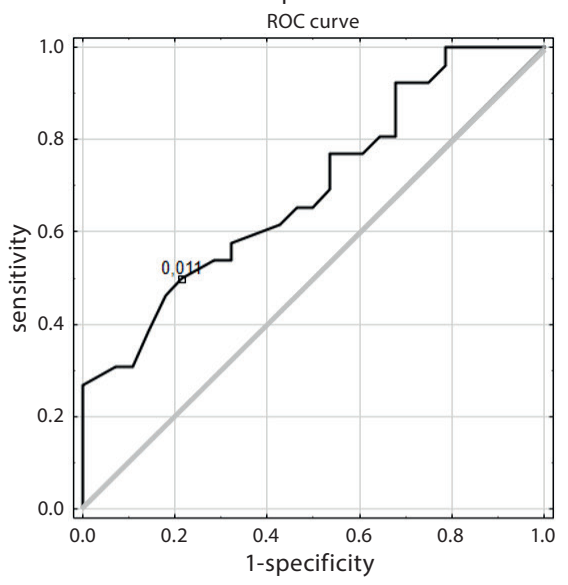

F model consisting of all 5 parameters

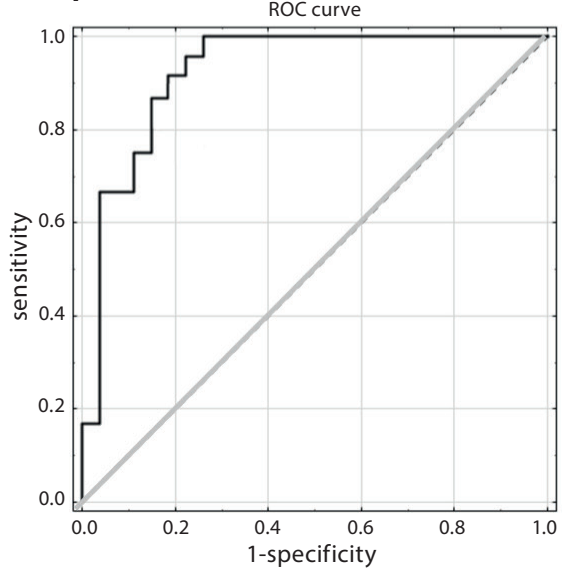

Fig. 3. ROC curves for LVRR prediction based on: HF symptom duration (A), LVED volume (B), troponin (C), NT-proBNP (D), and miR-133a levels (E), and ROC curve based on a model comprised of all parameters (F)

$\mathrm{ROC}$ - receiver operating characteristics; LVRR - left ventricular reverse remodeling; HF - heart failure.

Table 4. The predictive value of duration of disease, LVEDvol, hs-TnT, NT-proBNP, and myocardial miR-133a for LVRR prediction - multivariate logistic regression analysis

\begin{tabular}{|l|c|c|}
\multicolumn{1}{|c|}{ Parameters } & OR $(95 \% \mathrm{Cl})$ & $\mathrm{p}$-value \\
\hline Duration of disease & $0.97(0.94-1.01)$ & 0.09 \\
\hline LVEDvol & $0.99(0.98-1.00)$ & 0.03 \\
\hline hs-TnT & $<0.0001\left(1^{*} 10^{-7}-4^{*} 10^{12}\right)$ & 0.22 \\
\hline NT-proBNP & $0.25(0.03-1.98)$ & 0.19 \\
\hline miR-133a & $5.20(1.13-24.05)$ & 0.03 \\
\hline
\end{tabular}

\section{Discussion}

\section{Study findings}

The main findings of the study can be summarized as follows: firstly, LVRR was present in half of DCM patients. Secondly, of all the circulating and myocardial miRs under study, myocardial miR-133a alone differentiated LVRR-present and LVRR-absent groups. Thirdly, 
myocardial miR-133a was found to be a significant LVRR predictor. The multivariate regression model, including HF symptom duration, myocardial mir-133a, LVEDvol, troponin and NT-proBNP levels were found to be highly accurate for LVRR prediction in DCM.

\section{Predictors of left ventricle reverse remodeling in DCM}

Left ventricular reverse remodeling is of paramount importance in DCM. The rate of LVRR differs between studies and depends on many factors, such as the definition of LVRR, time of assessment, management strategy, etc. In our cohort, LVRR was present in half of the patients, which is in line with the literature. ${ }^{5,13}$ The division of DCM patients by the presence of reverse remodeling is dictated by its significance in prognosis and strong correlation with survival in DCM. ${ }^{5,14}$ Improvement in myocardial function can occur spontaneously and in response to HF therapy (drugs, cardiac devices). ${ }^{15,16}$ In our group, nearly $100 \%$ of patients were receiving adequate therapy as recommended by the ESC (95\% were on $\beta$-blockers, ACE-I and MRAs, and nearly $1 / 3$ had received cardiac resynchronization therapy (CRT)). ${ }^{1,13}$

The topic of LVRR has been intensively investigated and several LVRR independent predictors have been identified such as: longer symptom duration and higher NYHA class, larger LVEDd and LVEDvol and left atrium (LA) size, higher troponin and NT-proBNP levels, late gadolinium enhancement in magnetic resonance, left bundle branch block and longer QRS duration, and higher grade of mitral regurgitation. ${ }^{5,15,17}$ In our analysis, symptom duration, LVED volume, and troponin and NT-proBNP levels were significant LVRR predictors in DCM patients.

\section{Circulating and cardiac tissue miRs in cardiac remodeling and reverse remodeling}

Certain miRs under study, including miR-21, -26, -29, $-30,-33 a,-133 a$, and -423 , are known to be related to myocardial fibrosis, which leads to cardiac remodeling. ${ }^{9,18}$ Previously, we reported associations between circulating miR-26 and miR-30, and collagen volume fraction, which is a quantitative expression of myocardial fibrosis in DCM..${ }^{10}$ However, in this study, we found no connection between miR-26 or -30 and reverse remodeling.

Little is known about the role of miRs in cardiac reverse remodeling and LVRR, especially in DCM. Recently, it was shown that circulating miR-208a and miR-29a, which regulate hypertrophy, fibrosis and inflammation, were associated with LVRR. ${ }^{19,20}$ Furthermore, circulating miR-16, miR-27a, miR-101, and miR-150 were related to cardiac function improvement after myocardial infarction. In another study, higher expression of circulating miR-208, -208b and -499 were found in DCM patients when compared with healthy controls. ${ }^{21-23}$ Both Sucharov et al. and Shah et al. have recently reported dynamic changes in miRNA expression during LVRR, including an increase in miR-21, especially in response to $\beta$-blockers. ${ }^{24,25}$ However, we did not confirm any differences in miR-21 levels between DCM patients with and without LVRR. Moreover, Szczerba et al. found a significant decrease of miRs during pregnancy as protection from myocardial fibrosis during volume overload in pregnancy. ${ }^{26}$

Out of all the circulating and myocardial miRs under study here, we report for the first time the association between myocardial miR-133a and LVRR. Of note, none of the other circulating and tissue miRs, including circulating miR-133a, were related to LVRR. Based on previous laboratory studies, miR-133a has proven to have an important role in heart physiology and pathology, including cardiac development, hypertrophy, remodeling, and fibrosis. ${ }^{27-30}$ In a murine HF model, miR-133a was found to play an important role in the hypertrophic pathway. Interestingly, decreased levels of miR-133a cardiac tissue expression were linked with adverse cardiac remodeling, whereas increased miR-133a expression was related to a reduction of cardiac fibrosis and favorable ECM remodeling. ${ }^{31-33}$ Moreover, miR-133a was found to protect myocardial tissue and decrease apoptosis of cardiomyocytes after myocardial infarction. ${ }^{34}$ On the other hand, in recent studies, we did not observe any relations between either circulating or myocardial miR-133a with fibrosis, expressed either qualitatively or quantitatively. ${ }^{6}$ This is in line with the findings from other authors, who reported a lack of straightforward relations between particular miRs, including miR-133a, and cardiac fibrosis. ${ }^{33,35}$

Furthermore, several authors have reported close links between miR-133a and outcomes in various cardiac conditions. Circulating miR-133a was found to be a marker in the prediction of all-cause mortality and major adverse cardiovascular events in patients with coronary artery disease. ${ }^{22,36-39}$ Moreover, Besler et al. showed a connection between myocardial miR-133 levels and clinical outcomes in inflammatory cardiomyopathy. ${ }^{32}$ Widera et al. and Keller et al. showed an improvement in risk stratification with a panel consisting of circulating miRs, including miR-133, outperforming troponin level. ${ }^{37,40}$ In line with this, we have recently reported that myocardial miR-133a was an independent predictor of survival in DCM. ${ }^{6}$ Bearing this in mind, the present observation that myocardial miR-133a is independently associated with LVRR further reinforces the aforementioned findings that indicate that LVRR is one of the strongest factors influencing outcomes.

\section{Study limitations}

There are several study limitations which we would like to comment on. The study population is relatively small, but, on the other hand, the utilization of biopsy and tissue qRT-PCR to study miRs makes our study one of the largest 
in the field. Another limitation is the utilization of qPCR, which allows one to measure only selected miRs, whereas next generation sequencing enables identification of virtually all mRs. Thus, we concentrated on only a few miRs which were previously linked with fibrosis, and by doing so excluded hundreds of other miRs that may also have a role in fibrosis and LVRR.

\section{Conclusions}

Among circulating and tissue miRs: miR-21, -26, -29, $-30,-133 \mathrm{a}$, and -423 , only myocardial miR-133a expression was increased in patients with LVRR. Moreover, myocardial miR-133a was found to be an independent predictor of LVRR, and has been previously reported as a mortality predictor in DCM. This may indicate that miR-133a has a potential role in the reverse remodeling process in DCM and its potential role in anticipating LVRR in DCM. This might be further exploited by miR-133a expression level restoration with miRNA mimics.

\section{ORCID iDs}

Ewa Dziewięcka (1) https://orcid.org/0000-0002-7921-5447 Justyna Totoń-Żurańska (1) https://orcid.org/0000-0001-5970-238X Paweł Wołkow (10) https://orcid.org/0000-0002-9322-5545 Maria Kołton-Wróż (1) https://orcid.org/0000-0003-3968-0907 Ewelina Pitera (1) https://orcid.org/0000-0001-6208-5976 Sylwia Wiśniowska-Śmiałek (1) https://orcid.org/0000-0002-7563-6586 Lusine Khachatryan (10 https://orcid.org/0000-0002-0218-9092 Aleksandra Karabinowska (i) https://orcid.org/0000-0001-5181-6577 Maria Szymonowicz (10 https://orcid.org/0000-0002-8406-6212 Piotr Podolec (10) https://orcid.org/0000-0001-6101-2935 Paweł Rubiś (10) https://orcid.org/0000-0002-6979-3411

\section{References}

1. Ponikowski P, Voors AA, Anker SD, et al; ESC Scientific Document Group. 2016 ESC Guidelines for the diagnosis and treatment of acute and chronic heart failure of the European Society of Cardiology (ESC). Developed with the special contribution of the Heart Failure Association (HFA) of the ESC. Eur J Heart Fail. 2016;18(8):891-975.

2. Codd MB, Sugrue DD, Gersh BJ, Melton LJ. Epidemiology of idiopathic dilated and hypertrophic cardiomyopathy: A population-based study in Olmsted County, Minnesota, 1975-1984. Circulation. 1989; 80(3):564-572.

3. Elliott $P$, Andersson $B$, Arbustini $E$, et al. Classification of the cardiomyopathies: A position statement from the Society of Cardiology Working Group on Myocardial and Pericardial Diseases. Eur Heart J. 2008;29(2):270-276.

4. Brooks A, Schinde V, Bateman AC, Gallagher PJ. Interstitial fibrosis in the dilated non-ischaemic myocardium. Heart. 2003;89(10):1255-1256.

5. Merlo M, Pyxaras SA, Pinamonti B, Barbati G, Di Lenarda A, Sinagra G. Prevalence and prognostic significance of left ventricular reverse remodeling in dilated cardiomyopathy receiving tailored medical treatment. J Am Coll Cardiol. 2011;57(13):1468-1476.

6. Rubiś P, Totoń-Zurańska J, Wiśniowska-ŚmiałekS, et al.The relationship between myocardial fibrosis and myocardial microRNAs in dilated cardiomyopathy: A link between mir-133a and cardiovascular events. J Cell Mol Med. 2018;22(4):2514-2517.

7. Small EM, Frost RJA, Olson EN. MicroRNAs add a new dimension to cardiovascular disease. Circulation. 2010;121(8):1022-1032.

8. Wojciechowska A, Braniewska A, Kozar-Kamińska K. MicroRNA in cardiovascular biology and disease. Adv Clin Exp Med. 2017;26(5):865-874.

9. Vegter EL, van der Meer P, de Windt LJ, Pinto YM, Voors AA. MicroRNAs in heart failure: From biomarker to target for therapy. Eur J Hear Fail. 2016;18(5):457-468.
10. Rubiś P, Totoń-Żurańska J, Wiśniowska-Śmiałek S, et al. Relations between circulating microRNAs (miR-21, miR-26, miR-29, miR-30 and miR-133a), extracellular matrix fibrosis and serum markers of fibrosis in dilated cardiomyopathy. Int J Cardiol. 2017;231:201-206.

11. Chyrchel B, Totoń-Żurańska J, Kruszelnicka O, et al. Association of plasma miR-223 and platelet reactivity in patients with coronary artery disease on dual antiplatelet therapy: A preliminary report. Platelets. 2015;26(6):593-597.

12. Lang RM, Badano LP, Mor-Avi V, et al. Recommendations for cardiac chamber quantification by echocardiography in adults: An update from the American Society of Echocardiography and the European Association of Cardiovascular Imaging. Eur Heart J Cardiovasc Imaging. 2015;16(3):233-271.

13. Rubiś $P$, Wiśniowska-Śmiałek $S$, Biernacka-Fijałkowska B, et al. Left ventricular reverse remodeling is not related to biopsy-detected extracellular matrix fibrosis and serum markers of fibrosis in dilated cardiomyopathy, regardless of the definition used for LVRR. Heart Vessels. 2017;32(6):714-725.

14. Pinto YM, Elliott PM, Arbustini E, et al. Proposal for a revised definition of dilated cardiomyopathy, hypokinetic non-dilated cardiomyopathy, and its implications for clinical practice: A position statement of the ESC working group on myocardial and pericardial diseases. Eur Heart J. 2016;37(23):1850-1858.

15. Amorim S, Campelo M, Martins E, et al. Prevalence, predictors and prognosis of ventricular reverse remodeling in idiopathic dilated cardiomyopathy. Rev Port Cardiol. 2016;35(5):253-260.

16. Ikeda Y, Inomata T, Fujita T, et al. Cardiac fibrosis detected by magnetic resonance imaging on predicting time course diversity of left ventricular reverse remodeling in patients with idiopathic dilated cardiomyopathy. Heart Vessels. 2016;31(11):1-10.

17. Choi J-O, Kim EY, Lee GY, et al. Predictors of left ventricular reverse remodeling and subsequent outcome in nonischemic dilated cardiomyopathy. Circ J. 2013;77(2):462-469.

18. Yu B, Li W, Al F, Chen Z. MicroRNA-33a deficiency inhibits proliferation and fibrosis through inactivation of TGF- $\beta / S$ mad pathway in human cardiac fibroblasts. Pharmazie. 2017;72(8):456-460.

19. Liu X, Wang L, Li H, et al. Coactivator-associated arginine methyltransferase 1 targeted by miR-15a regulates inflammation in acute coronary syndrome. Atherosclerosis. 2014;233(2):349-356.

20. Kuosmanen SM, Hartikainen J, Hippeläinen M, Kokki H, Levonen A-L, Tavi P. MicroRNA profiling of pericardial fluid samples from patients with heart failure. PLoS One. 2015;10(3):e0119646.

21. Li Q, Xie J, Li R, et al. Overexpression of microRNA-99a attenuates heart remodelling and improves cardiac performance after myocardial infarction. J Cell Mol Med. 2014;18(5):919-928.

22. Devaux Y, Vausort M, McCann GP, et al. A panel of 4 microRNAs facilitates the prediction of left ventricular contractility after acute myocardial infarction. PLoS One. 2013;8(8):e70644.

23. Satoh M, Minami Y, Takahashi Y, Tabuchi T, Nakamura M. Expression of microRNA-208 is associated with adverse clinical outcomes in human dilated cardiomyopathy. J Card Fail. 2010;16(5):404-410.

24. Sucharov CC, Kao DP, Port JD, et al. Myocardial microRNAs associated with reverse remodeling in human heart failure. JCI Insight. 2017; 2(2):1-16.

25. Shah R, Ziegler O, Yeri A, et al. MicroRNAs associated with reverse left ventricular remodeling in humans identify pathways of heart failure progression. Circ Heart Fail. 2018;11(2):e004278.

26. Szczerba E, Zajkowska A, Bochowicz A, et al. Rise in antifibrotic and decrease in profibrotic microRNA protect the heart against fibrosis during pregnancy: A preliminary study. Adv Clin Exp Med. 2018;27(7): 867-872.

27. Sucharov $C$, Bristow MR, Port JD. miRNA expression in the failing human heart: Functional correlates. J Mol Cell Cardiol. 2008;45(2): 185-192.

28. Thum T, Galuppo P, Wolf $C$, et al. MicroRNAs in the human heart: A clue to fetal gene reprogramming in heart failure. Circulation. 2007; 116(3):258-267.

29. Sayed D, Hong C, Chen IY, Lypowy J, Abdellatif M. MicroRNAs play an essential role in the development of cardiac hypertrophy. Circ Res. 2007;100(3):416-424.

30. Ivey KN, Muth A, Arnold J, et al. MicroRNA regulation of cell lineages in mouse and human embryonic stem cells. Cell Stem Cell. 2008;6(23): 219-229. 
31. Carè A, Catalucci D, Felicetti F, et al. MicroRNA-133 controls cardiac hypertrophy. Nat Med. 2007;13(5):613-618.

32. Besler C, Urban D, Watzka S, et al. Endomyocardial miR-133a levels correlate with myocardial inflammation, improved left ventricular function, and clinical outcome in patients with inflammatory cardiomyopathy. Eur J Heart Fail. 2016;18(12):1442-1451.

33. Castaldi A, Zaglia T, Di Mauro V, et al. MicroRNA-133 modulates the $\beta 1$-adrenergic receptor transduction cascade. Circ Res. 2014; 115(2):273-283.

34. He B, Xiao J, Ren A-J, et al. Role of miR-1 and miR-133a in myocardial ischemic postconditioning. J Biomed Sci. 2011;18(1):22.

35. Saxena A, Tabin CJ. miRNA-processing enzyme Dicer is necessary for cardiac outflow tract alignment and chamber septation. Proc Natl Acad Sci U S A. 2010;107(1):87-91.

36. Wang F, Long G, Zhao C, et al. Plasma microRNA-133a is a new marker for both acute myocardial infarction and underlying coronary artery stenosis. J Transl Med. 2013;11:222.
37. Widera C, Gupta SK, Lorenzen JM, et al. Diagnostic and prognostic impact of six circulating microRNAs in acute coronary syndrome. J Mol Cell Cardiol. 2011;51(5):872-875.

38. Gacoń J, Kabłak-Ziembicka A, Stępień E, et al. Decyzyjne mikroRNA (miR-124, -133a/b, -34a i-134) u pacjentów z zamkniętym naczyniem odpowiedzialnym za zawałzostrym zespołem wieńcowym. KardiolPol. 2016;74(3):280-288.

39. Eitel I, Adams V, Dieterich $P$, et al. Relation of circulating microRNA133a concentrations with myocardial damage and clinical prognosis in ST-elevation myocardial infarction. Am Heart J. 2012;164(5): 706-714.

40. Keller T, Boeckel JN, Groß S, et al. Improved risk stratification in prevention by use of a panel of selected circulating microRNAs. Sci Rep. 2017;7(1):4511. 